\title{
Development of an on-site diagnostic system for infectious diseases: evaluation using blood samples containing the bovine leukemia DNA
}

\author{
Yasuko Yamazaki ${ }^{1}$, Uraiwan $\mathrm{Seo}^{1}$, Konomu Nagao ${ }^{2}$, Hirohisa Mekata ${ }^{3}$, and Wataru \\ Yamazaki $^{1}$ \\ ${ }^{1}$ Kyoto University \\ ${ }^{2}$ University of Miyazaki \\ ${ }^{3}$ Miyazaki Daigaku
}

April 28, 2020

\begin{abstract}
Along with progress in globalization of society, the spread of infectious diseases has accelerated worldwide. Although the deployment of highly sensitive genetic tests is essential for early diagnosis and early containment of potential epidemics, tedious and expensive nucleic acid extraction steps represent a major drawback. Here we developed a simple and rapid DNA extraction method, named as an EZ-Fast kit, applicable to the epidemic field setting. The kit does not require advanced laboratory equipment or expensive DNA extraction kits and achieves crude DNA extraction within 10 min at extremely low cost. When combined with real-time PCR and LAMP analyses, the performance of the method, using 183 bovine blood samples, was similar to that of the existing DNA extraction method: 92.5\% (135/146) (real-time PCR) and 93.7\% (133/142) (LAMP) diagnostic sensitivities, and $100 \%$ diagnostic specificities. The developed system provides a powerful tool to facilitate on-site diagnosis in an epidemic field setting.
\end{abstract}

Development of an on-site diagnostic system for infectious diseases: evaluation using blood samples containing the bovine leukemia DNA

Yasuko Yamazaki ${ }^{1}, \mathrm{Uraiwan}_{\mathrm{Seo}}{ }^{1}, \mathrm{Konomu} \mathrm{Nagao}^{2}$, Hirohisa Mekata ${ }^{3}$, Wataru Yamazaki ${ }^{1 *}$

${ }^{1}$ Center for Southeast Asian Studies, Kyoto University, 46 Shimoadachicho, Yoshida, Sakyo-ku, Kyoto 6068501, Japan.

${ }^{2}$ Department of Veterinary Science, Faculty of Agriculture, University of Miyazaki, 1-1 Gakuen Kibanadainishi, Miyazaki, Miyazaki, 889-2192 Japan.

${ }^{3}$ Organization for Promotion of Tenure Track, University of Miyazaki, Miyazaki 889-2192, Japan

Running head: On-site diagnosis in epidemic field settings

*Corresponding author:

Wataru Yamazaki, Center for Southeast Asian Studies, Kyoto University, 46 Shimoadachicho, Yoshida, Sakyo-ku, Kyoto 606-8501, Japan

Tel.: +81 (0) 75-753-9618; Fax: +81 (0) 75-761-2701

E-mail: yamazaki@cseas.kyoto-u.ac.jp 


\section{Summary}

Along with progress in globalization of society, the spread of infectious diseases has accelerated worldwide. Although the deployment of highly sensitive genetic tests is essential for early diagnosis and early containment of potential epidemics, tedious and expensive nucleic acid extraction steps represent a major drawback. Here we developed a simple and rapid DNA extraction method, named as an EZ-Fast kit, applicable to the epidemic field setting. The kit does not require advanced laboratory equipment or expensive DNA extraction kits and achieves crude DNA extraction within $10 \mathrm{~min}$ at extremely low cost. When combined with real-time PCR and LAMP analyses, the performance of the method, using 183 bovine blood samples, was similar to that of the existing DNA extraction method: 92.5\% (135/146) (real-time PCR) and 93.7\% (133/142) (LAMP) diagnostic sensitivities, and 100\% diagnostic specificities. The developed system provides a powerful tool to facilitate on-site diagnosis in an epidemic field setting.

Keywords: EZ-Fast; Field setting; LAMP; On-site; Real-time PCR

Introduction

With progress in globalization, the risk of spreading human and animal infectious diseases has accelerated worldwide (Howson et al, 2018; Huang et al, 2020; OIE, 2018b; WHO, 2020; Yamazaki et al, 2019). Pandemic spread of human pathogens such as SARS-CoV-2 (COVID-19) can cause numerous fatalities worldwide (Huang et al, 2020; WHO, 2020). Further, transboundary animal diseases cause serious global economic damage to livestock and meat industries worldwide (Howson et al, 2018; OIE, 2018b; Yamazaki et al, 2013, 2019). It is therefore important to minimize the spread of pathogens through correct and rapid diagnosis of diseases of humans and animals. This in turn highlights the necessity for on-site diagnosis in epidemic field settings (Almassian, et al, 2013; Armson et al, 2017; Howson et al, 2018; Madi et al, 2012).

The immunochromatographic assay (ICA) is widely used for rapid screening on farms (OIE, 2018b). Although ICA is useful for rapid diagnosis of infected animals with high pathogen levels, its lack of sensitivity is a major drawback, because detection using ICA requires [?] $10^{5}-10^{6}$ infectious units per $1 \mathrm{~g}$ or $1 \mathrm{ml}$ of sample, potentially leading to false-negative diagnoses of recently-infected animals with a low number of pathogens (OIE, 2018b).

Deployment of genetic tests for on-site diagnosis in epidemic field settings is an attractive option to achieve early containment because of their high diagnostic performance (Almassian, et al, 2013; Kurosaki et al, 2016; Howson et al, 2018). For example, several studies achieved expedited on-site diagnosis in epidemic field settings of humans and animals through the use of portable, battery-powered real-time PCR and loopmediated isothermal amplification (LAMP) devices (Armson et al, 2017; Howson et al, 2018; Kurosaki, et al, 2016; Madi et al, 2012). The nucleic acid extraction step requires expensive commercial extraction kits, however, and is therefore a major disadvantage. Therefore, a simple dilution technique with nuclease-free water was applied to successfully detect target pathogens (Howson et al, 2018; Waters et al, 2014). However, this simple technique decreases analytical sensitivity (limit of detection [LOD]) in the range of a $10^{1}-10^{3}$ fold reduction compared with conventional laboratory nucleic acid extraction methods (Howson et al, 2018). More sophisticated approaches that minimize false-negative results will enable simple and sensitive diagnosis.

Sodium dodecyl benzenesulfonate (SDBS) is an attractive candidate to develop a simple, rapid, and costeffective nucleic acid extraction method using real-time PCR and LAMP amplification (Sekikawa, 2017). SDBS is an analog of sodium dodecyl sulfate (SDS), which provides equivalent performance for DNA extraction from cells with lower inhibitory effects than SDS (Sekikawa, 2017). Here, we developed a simple and cost-effective on-site diagnosis system through the combination of rapid DNA extraction using SDBS, named as an EZ-Fast kit, and real-time PCR and LAMP amplifications that maintains diagnostic accuracy. For this purpose, we used 183 bovine blood samples containing bovine leukemia virus (BLV) to evaluate diagnostic performance compared with a conventional automated DNA extraction method.

2. Materials and Methods

The EZ-Fast kit for on-site diagnosis was developed by combining a portable heat-block and a dry-cell 
battery-powered tabletop centrifuge, which achieves simple DNA extraction using SDBS. Unpurified DNA is subsequently amplified using a real-time PCR and a portable battery-powered LAMP device (Fig. 1). To evaluate the performance of this kit, we compared results with those of the gold standard (conventional method) real-time PCR and LAMP analyses of DNA using an automatic nucleic acid extractor.

\section{2-1. Bovine blood samples.}

We used 183 bovine blood samples obtained from cattle farms in Kagoshima, Miyazaki, and Oita prefectures in Japan from March 2017 to January 2020. EDTA was added to these samples, which were collected at the farms, kept cool, and delivered to our laboratory where they were stored $4{ }^{\circ} \mathrm{C}$. DNA was immediately extracted from the remaining bovine blood samples and used for real-time PCR and LAMP analyses; otherwise, they were stored at $-80{ }^{\circ} \mathrm{C}$.

\section{2-2. DNA extraction using the EZ-Fast kit.}

For on-site diagnosis in epidemic field setting, each crude DNA sample was prepared as follows: $0.5 \mathrm{ml}$ of bovine blood was added to a $1.5-\mathrm{ml}$ microcentrifuge tube, and $0.5 \mathrm{ml}$ of SDBS (Tokyo Chemical Industry Co., Tokyo, Japan) was added and mixed by pipetting 5-10 times. The sample tube was placed in a portable heat block (Mini heating dry bath incubator, MD-MINI, Major Science, Co. Ltd., Saratoga, CA, USA), incubated at $95{ }^{\circ} \mathrm{C}$ for $5 \mathrm{~min}$, and centrifuged in a dry-cell battery-powered tabletop centrifuge (Puchimaru 8, Wakenbtech, Co., Ltd., Kyoto, Japan) for $5 \mathrm{~min}$ at full speed (6,000 rpm, 1,260-2,840 x $\mathrm{g}$ ) at room temperature. A $20-\mu \mathrm{l}$ sample of the supernatant was transferred to a new 0.2 -ml microcentrifuge tube for real-time PCR and LAMP analyses. Special attention was payed to retrieving the very top layer of the supernatant to avoid contamination with solid blood debris that may contain DNA polymerase inhibitors. The protocol for DNA amplification steps is shown in Fig. 1. Each 200- $\mu$ l blood sample was then added to a 1.5-ml screw-capped tubes and added to $50 \mu \mathrm{l}$ of RNase-free water using the magLEAD 6gC automated extraction platform (Precision System Science Co., Matsudo, Japan) for conventional real-time PCR and LAMP analyses.

\section{2-3. Real-time PCR.}

Using a LightCycler 480 System II (Roche Molecular Systems, Pleasanton, CA, USA) or a QuantStudio 3 (Thermo Fisher Scientific, Inc., Waltham, MA, USA), real-time PCR was performed according to the World Organization for Animal Health (OIE) Manual of Diagnostic Tests and Vaccines for Terrestrial Animals (2018a) based on pol sequences reported by Rola-Łuszczak, and colleagues (2013). Reactions were slightly modified using shorter times for denaturation and annealing according to the instructions provided with the probe qPCR mix (TaKaRa Bio Inc., Otsu, Japan). Briefly, $20 \mu \mathrm{l}$ of rPCR reaction mixtures comprising 10 $\mu \mathrm{l}$ of $2 \mathrm{x}$ probe qPCR mix (TaKaRa Bio), $0.08 \mu \mathrm{l}$ of each primer $(100 \mathrm{pmol} / \mu \mathrm{l}$; Hokkaido System Science, Sapporo, Japan), $0.04 \mu \mathrm{l}$ of probe (100 pmol/ $\mu \mathrm{l}$; Hokkaido System Science), $7.8 \mu \mathrm{l}$ of nuclease-free water (TaKaRa Bio), and $2 \mu \mathrm{l}$ of the DNA template. The cycling conditions were as follows: one cycle at $95{ }^{\circ} \mathrm{C}$ for $20 \mathrm{~s}, 45$ cycles each at $95{ }^{\circ} \mathrm{C}$ for $5 \mathrm{~s}$, and $60{ }^{\circ} \mathrm{C}$ for $30 \mathrm{~s}$. The threshold cycle $\left(\mathrm{C}_{\mathrm{T}}\right)$ value used as the cut-off was 40.95 according to the OIE Manual (2018a).

\section{2-4. LAMP.}

LAMP was performed using a Genie III (OptiGene, Horsham, UK) according to the LTR sequences reported by Komiyama, et al. (2009) with a slight modification as follows: Amplification was performed at $63{ }^{\circ} \mathrm{C}$ for 30 min, followed by inactivation at $98{ }^{\circ} \mathrm{C}$ for $2 \mathrm{~min}$, and cooling to $80^{\circ} \mathrm{C}$ for annealing, with ramping at $0.05^{\circ} \mathrm{C} / \mathrm{s}$. The 20- $\mu$ l LAMP reaction comprised $10 \mu$ l of a Loopamp DNA amplification kit (Eiken Chemical, Co., Ltd., Tokyo, Japan) or an in-house LAMP reaction mixture with the identical composition (Yashiki et. al., 2019); $0.32 \mu \mathrm{l}$ each of FIP and BIP primers $(100 \mathrm{pmol} / \mu \mathrm{l}) ; 0.16 \mu \mathrm{l}$ each of LF and LB primers $(100 \mathrm{pmol} / \mu \mathrm{l}) ; 0.04$ $\mu \mathrm{l}$ each of F3 and B3 primers (100 pmol/ $\mu \mathrm{l}) ; 0.8 \mu \mathrm{l}$ of Bst polymerase 2.0; $0.8 \mu \mathrm{l}$ of CFI (Colori- Fluorescent Indicator, comprising $967 \mu \mathrm{l}$ of distilled water, $30 \mu \mathrm{l}$ of $100 \mathrm{mmol} / \mu \mathrm{l}$ hydroxynaphthol blue [MP Biomedicals, Aurora, OH, USA], and $3 \mu \mathrm{l}$ of Gel Green [x10 000; Biotium, Hayward, CA, USA]); $5.36 \mu$ l of nucleasefree water; and $2 \mu \mathrm{l}$ of the DNA template. CFI was added to accelerate the amplification rate and enable 
analysis of fluorescence (Hayashida et., al., 2015; Yashiki et. al., 2019). LAMP primers were produced by Hokkaido System Science (Sapporo, Japan) (column-grade purification). The LAMP results were interpreted as positive when the fluorescence intensity reached 10,000 within 30 min of amplification, and the annealing temperature (Ta) ranged between $81.5^{\circ} \mathrm{C}$ and $84.5^{\circ} \mathrm{C}$. Time-of-positivity (Tp) was automatically calculated using the Genie III setting. Details of the primers and probes are shown in Table 1 (Rola-Łuszczak et al, 2013; OIE, 2018; Komiyama et al, 2009).

\section{2-5. LOD}

The LOD was determined using 10-fold serial dilutions of BLV DNA-positive blood samples. We prepared five randomly chosen pooled BLV DNA-negative bovine blood samples, and the real-time PCR and LAMP assays were performed as described above. When a sample was positive or negative in duplicate analyses, the result was interpreted as a positive in both assays.

\section{Results and Discussion}

The results of the conventional and the EZ-Fast extraction methods were highly consistent. Diagnostic sensitivities and specificities were $92.5 \%(135 / 146)$ and $100 \%$ (37/37) for real-time PCR and 93.6\% (132/141) and $100 \%(42 / 42)$ for LAMP (Tables 2 and 3). In contrast to the conventional automatic DNA extraction platform, which requires 26 min to complete and costs $>\$ 3.50$ (USD) for DNA extraction reagents, the EZ-Fast kit required $10 \mathrm{~min}$ for crude DNA extraction and costs $<\$ 0.10$ (USD) (Fig. 1).

The LOD of EZ-Fast used detection was significantly lower ( $>10$-fold) than that of the conventional detection method (Table 4). The LOD of real-time PCR was achieved for the conventional and the EZ-Fast extraction methods for samples diluted $10^{3}$-fold. However, at $10^{4}$-fold dilution, the conventional method yielded one positive and one negative in duplicate analyses, although negative in the EZ-Fast extraction. Compared with the real-time PCR assay, the LAMP assay yielded six false-negative and one false-positive samples using the conventional method and three samples using the EZ-Fast kit (Tables 2 and 3), which is likely explained by the difference between the LODs of the LAMP vs real-time PCR assay (Table 4).

The average $\mathrm{C}_{\mathrm{T}}$ value of the positive sample was 2.65-times higher using the EZ-Fast kit, which dilutes blood 1:2 with SDBS, whereas the conventional method adds $200 \mu \mathrm{l}$ of whole blood to $50 \mu \mathrm{l}$ of nuclease-free water. Theoretically, the difference in the BLV-provirus concentrations between the two methods is 8-fold, which corresponds to $2^{3}\left(\mathrm{C}_{\mathrm{T}}\right.$ values 3$)$. The average $\mathrm{C}_{\mathrm{T}}$ value of the positive sample was 2.65 , as expected. Similarly, in the LAMP assay, the EZ-Fast kit yielded eight false negatives (Table 3). Although real-time PCR used the EZ-Fast kit reproducibly amplified target DNA, individual samples may be affected by different inhibitory effects of blood-derived substances (Schrade et. al., 2012; Wiemels et. al., 1999; Wilson, 1997). Therefore, a qualitative interpretation should be employed, regardless of $\mathrm{C}_{\mathrm{T}}$ values, suggesting that the developed system is unsuitable for quantifying copy number.

Among 183 bovine blood samples, the real-time PCR data for one sample (No. 167) were discrepant $\left(\mathrm{C}_{\mathrm{T}}\right.$ 30.63, automatic extraction and $\mathrm{C}_{\mathrm{T}} 22.48$, EZ-Fast extraction) (Table 5 and Supplemental Table 1). Considering the possibility of mixing samples, we repeated both DNA extraction methods in duplicate using the blood samples stored at $-80{ }^{\circ} \mathrm{C}$. The results were equivalent to those of the initial analyses: $\mathrm{C}_{\mathrm{T}} 30.37$ (conventional automatic extraction) and $\mathrm{C}_{\mathrm{T}} 24.59$ (EZ-Fast extraction). We therefore tested 10-fold serial dilutions of automatically extracted and crude DNAs from the latter and evaluated LODs using the realtime PCR and LAMP assays performed in duplicate (Table 5). In both assays, crude DNA obtained using the EZ-Fast kit achieved $10^{4}-10^{5}$ greater sensitivity compared with the conventional automatic extraction method (Table 5). Although we are unable to explain the reason for this discrepancy, we determined that more target DNA was contained in the EZ-Fast-extracted crude supernatant than in DNA automatically extracted from whole blood.

Compared with SDS, SDBS performs equally well for extracting DNA from cells with reduced inhibitory effects on real-time PCR reactions when the SDS in the samples is neutralized with 5\% Tween 20 (Sekikawa, 2017). Here we were surprised to find that simple heating at $95{ }^{\circ} \mathrm{C}$ for 5 min followed by 5 -min centrifugation 
using a portable tabletop centrifuge operated at full speed $(1,260-2,840 \times \mathrm{g})$ was sufficient to obtain crude DNA suitable for real-time PCR and LAMP amplifications, despite significant contamination with blood components. Further, tedious neutralization using a Tween 20 solution was not required for reproducible DNA amplification with both amplification techniques. The developed system may therefore be easily applied to on-site diagnosis in an epidemic setting for detecting pathogens that require detection of DNA in blood, including serum and plasma, such as African swine fever and protozoan diseases.

\section{Conclusions}

We developed an on-site diagnostic system suitable for epidemic field settings that does not require advanced laboratory equipment and expensive DNA extraction kits. This economical, easy, rapid, highly sensitive and specific system promises to provide an important new tool for routine veterinary medicine as well as for preventing and combating devastating pandemics such as that caused by SARS-CoV-2.

Acknowledgments

The authors thank Mari Yamamoto for technical assistance. This research was supported by JSPS KAKENHI, Grant Number JP18K05535, JSPS Bilateral Open Partnership Joint Research Projects and AMED under Grant Number JP19jk0210007.

Data availability Statement

The data that supports the findings of this study are available in the supplementary material of this article.

Ethics Statement

The authors confirm that the ethical policies of the journal, as noted on the journal's author guidelines page, have been adhered to and the appropriate informed client consent has been received for the sample collection of bovine blood from client-owned cattle.

Conflict of Interest Statement

The authors declare that they have no conflict of interest.

References

1. Almassian, D. R., Cockrell, L. M., Nelson, W. M. (2013). Portable nucleic acid thermocyclers. Chemical Society Reviews, 42(22), 8769-8798. 10.1039/c3cs60144g.

2. Armson B, Fowler VL, Tuppurainen ESM, Howson ELA, Madi M, Sallu R, Kasanga CJ, Pearson C, Wood J, Martin P, Mioulet V, King DP. 2017. Detection of Capripoxvirus DNA using a fieldready nucleic acid extraction and real-time PCR platform. Transbound Emerg Dis.64: 994-997. doi: $10.1111 /$ tbed.12447.

3. Hayashida K., Kajino K., Hachaambwa L., Namangala B., Sugimoto C. 2015. Direct blood dry LAMP: a rapid, stable, and easy diagnostic tool for Human African Trypanosomiasis. PLoS Negl. Trop. Dis. 9: e0003578. doi: 10.1371/journal.pntd.0003578.

4. Howson, E., Armson, B., Lyons, N. A., Chepkwony, E., Kasanga, C. J., Kandusi, S., Ndusilo, N., Yamazaki, W., Gizaw, D., Cleaveland, S., Lembo, T., Rauh, R., Nelson, W. M., Wood, B. A., Mioulet, V., King, D. P., \& Fowler, V. L. (2018). Direct detection and characterization of foot-and-mouth disease virus in East Africa using a field-ready real-time PCR platform. Transboundary and emerging diseases ,65 (1), 221-231. doi.org/10.1111/tbed.12684

5. Huang C, Wang Y, Li X, Ren L, Zhao J, Hu Y, Zhang L, Fan G, Xu J, Gu X, Cheng Z, Yu T, Xia J, Wei Y, Wu W, Xie X, Yin W, Li H, Liu M, Xiao Y, Gao H, Guo L, Xie J, Wang G, Jiang R, Gao Z, Jin Q, Wang J, Cao B. (2020). Clinical features of patients infected with 2019 novel coronavirus in Wuhan, China. Lancet. 395(10223):497-506. doi: 10.1016/S0140-6736(20)30183-5.

6. Komiyama C., Suzuki K., Miura Y., Sentsui H. (2009). Development of loop-mediated isothermal amplification method for diagnosis of bovine leukemia virus infection. J. Virol. Methods 157: 175-179. doi: 10.1016/j.jviromet.2008.12.015. 
7. Kurosaki Y., Magassouba N., Oloniniyi O. K., Cherif M. S., Sakabe S., Takada A., Hirayama K., Yasuda J. (2016). Development and evaluation of reverse transcription-loop-mediated isothermal amplification (RT-LAMP) assay coupled with a portable device for rapid diagnosis of Ebola virus disease in Guinea. PLoS Negl. Trop. Dis. 10: e0004472. doi: 10.1371/journal.pntd.0004472.

8. Madi M., Hamilton A., Squirrell D., Mioulet V., Evans P., Lee M., \& King D. P. (2012). Rapid detection of foot-and-mouth disease virus using a field-portable nucleic acid extraction and real-time PCR amplification platform. The Veterinary Journal, 193(1), 67-72.

9. Rola-Łuszczak M., Finnegan C., Olech M., Choudhury B., Kuźmak J. (2013). Development of an improved real time PCR for the detection of bovine leukaemia provirus nucleic acid and its use in the clarification of inconclusive serological test results. J. Virol. Methods 189: 258-264. doi: 10.1016/j.jviromet.2013.02.014.

10. Sekikawa, T. (2017). A new immunomagnetic bead separation-surfactant extraction treatment protocol for rapid and sensitive quantitative PCR detection of Cryptosporidium parvum DNA. Wat Sci Tech: Wat Sup. 17-1, 161-168.

11. Schrader, C., A. Schielke, L. Ellerbroek, and R. Johne. (2012). PCR inhibitors - occurrence, properties and removal. J Appl Microbiol. 113, 1014-1026. doi: 10.1111/j.1365-2672.2012.05384.x.

12. Waters RA, Fowler VL, Armson B, Nelson N, Gloster J, Paton DJ, King DP. (2014) Preliminary Validation of Direct Detection of Foot-And-Mouth Disease Virus within Clinical Samples Using Reverse Transcription Loop-Mediated Isothermal Amplification Coupled with a Simple Lateral Flow Device for Detection. PLoS ONE 9(8): e105630. doi:10.1371/journal.pone.0105630.

13. Wiemels, J.L., Cazzaniga, G., Daniotti, M., Eden, O.B., Addison, G.M., Masera, G., Saha, V., Biondi, A., Greaves, M.F. (1999). Prenatal origin of acute lymphoblastic leukaemia in children. Lancet. 354(9189):1499-1503.

14. Wilson, I. G. (1997). Inhibition and facilitation of nucleic acid amplification. Applied and Environmental Microbiology, 63,3741-3751.

15. World Health Organization (WHO). 2020. Coronavirus disease 2019 (COVID-19) Situation Report59. https://apps.who.int/iris/bitstream/handle/10665/331597/nCoVsitrep19Mar2020-eng.pdf., 2020 (accessed 1 April 2020).

16. World Organization for Animal Health (OIE). 2018a. Enzootic bovine leucosis (Chapter 3.4.9). pp. 1113-1124. In : Manual of Diagnostic Tests and Vaccines for Terrestrial Animals, Paris.

17. World Organization for Animal Health (OIE). 2018b. Avian Influenza (Chapter 3.3.4). pp. 821-843. In : Manual of Diagnostic Tests and Vaccines for Terrestrial Animals, Paris.

18. Yamazaki W., Mioulet V., Murray L., Madi M., Haga T., Misawa N., Horii Y., King D. P. 2013. Development and evaluation of multiplex RT-LAMP assays for rapid and sensitive detection of footand-mouth disease virus. J. Virol. Methods 192: 18-24. doi: 10.1016/j.jviromet.2013.03.018.

19. Yamazaki, W., Makino, R., Nagao, K., Mekata, H., \& Tsukamoto, K. (2019). New Micro-amount of Virion Enrichment Technique (MiVET) to detect influenza A virus in the duck faeces. Transbound Emerg Dis, 66, 341-348. doi: org/10.1111/tbed.13027.

20. Yashiki N, Yamazaki Y, Subangkit M, Okabayashi T, Yamazaki W, Goto Y.2019. Development of a LAMP assay for rapid and sensitive detection and differentiation of Mycobacterium avium subsp. aviumand subsp. hominissuis . Lett Appl Microbiol. 69: 155-160. doi: 10.1111/lam.13188.

\section{Table 1. Primers used for real-time PCR LAMP and assays for the BLV DNA.}

\begin{tabular}{ll}
\hline Primer & Sequences (5'-3') \\
\hline Real-time PCR & Real-time PCR \\
MRBLVL & CCTCAATTCCCTTTAAACTA \\
MRBLVR & GTACCGGGAAGACTGGATTA
\end{tabular}




\begin{tabular}{lll}
\hline Primer & Sequences $\left(5^{\prime}-3^{\prime}\right)$ & Reference \\
\hline MRBLV probe & 6FAM-GAACGCCTCCAGGCCCTTCA-BHQ1 & \\
LAMP & & Komiyama et al, 2009 \\
FIP & AGCAGGTGAGGTCAGCAGCTTGGCTAGAATCCCCGTACC & \\
BIP & CTGTCGAGTAGCGGCACCAAAGAGAGCTCAGGACCGAG & \\
F3 & AGACGTCAGCTGCCAGAA & \\
B3 & GGATAGCCGACAAGAAGGT & \\
FLP & GGAAAGGGGAAGTTGGGGA & \\
BLP & CGTTCTTCTCCTGAGACCCTCGT & \\
\hline
\end{tabular}

Table 2. Diagnostic performance of real-time PCR and LAMP using automatically or EZ-Fast-extracted DNAs.

\begin{tabular}{|c|c|c|c|c|}
\hline & $n$ & $\begin{array}{l}\text { Real-time PCR } \\
\text { with } \\
\text { EZ-Fast-extracted } \\
\text { DNAs }\end{array}$ & $\begin{array}{l}\text { LAMP with } \\
\text { automatically } \\
\text { extracted DNAs }\end{array}$ & $\begin{array}{l}\text { LAMP with } \\
\text { EZ-Fast-extracted } \\
\text { DNAs }\end{array}$ \\
\hline $\begin{array}{l}\text { Real-time } \\
\text { PCR-positive with } \\
\text { automatically } \\
\text { extracted DNAs }\end{array}$ & 146 & $\begin{array}{l}\text { 135/146 (Sen, } \\
92.5 \% \text { ) }\end{array}$ & $\begin{array}{l}\text { 141/146 (Sen, } \\
96.6 \%)\end{array}$ & $\begin{array}{l}\text { 133/146 (Sen, } \\
91.1 \% \text { ) }\end{array}$ \\
\hline $\begin{array}{l}\text { Real-time } \\
\text { PCR-negative with } \\
\text { automatically } \\
\text { extracted DNAs }\end{array}$ & 37 & 37/37 (Spe, 100\%) & $36 / 37$ (Spe, $97.3 \%)$ & $37 / 37$ (Spe, 100\%) \\
\hline
\end{tabular}

Sen, Diagnostic sensitivity. Spe, Diagnostic specificity.

Table 3. Diagnostic performance of LAMP using automatically and EZ-Fast-extracted DNAs.

\begin{tabular}{|c|c|c|}
\hline & $n$ & $\begin{array}{l}\text { LAMP with EZ-Fast-extracted } \\
\text { DNAs }\end{array}$ \\
\hline $\begin{array}{l}\text { LAMP-positive with } \\
\text { automatically extracted DNAs }\end{array}$ & 141 & 133/141 (Sen, 94.3\%) \\
\hline $\begin{array}{l}\text { LAMP-negative with } \\
\text { automatically extracted DNAs }\end{array}$ & 42 & $42 / 42$ (Spe, $100 \%)$ \\
\hline
\end{tabular}

Sen, Diagnostic sensitivity. Spe, Diagnostic specificity.

Table 4. Analytical sensitivities of real-time PCR and LAMP assays.

\begin{tabular}{lll}
\hline Assays & Dilutions of pooled BLV-positive blood samples & Dilutions of pooled BLV-positive blood \\
\hline & $10^{-1}$ & $10^{-2}$ \\
Real-time PCR $\left(\mathrm{C}_{\mathrm{T}}\right)$ & & 32.82 \\
Automatically extracted DNAs & 29.79 & 36.54 \\
EZ-Fast-extracted DNAs & 33.92 & $14: 00$
\end{tabular}




\begin{tabular}{lll}
\hline Assays & Dilutions of pooled BLV-positive blood samples & Dilutions of pooled BLV-positive blood \\
\hline EZ-Fast-extracted DNAs & $14: 07$ & $16: 23$ \\
\hline
\end{tabular}

No. $\mathrm{C}_{\mathrm{T}}$, no threshold cycle values detected using real-time PCR. No. Tp, time-of-positivity values undetectable using LAMP.

+ , In a duplicate analysis, one sample was positive and one was negative using the real-time PCR or LAMP reaction.

Table 5. Analytical sensitivities of samples with discrepant results using automatically and EZ-Fast-extracted DNAs (No. 167).

\begin{tabular}{lll}
\hline Assays & Dilutions of pooled BLV-positive blood samples & Dilutions of pooled BLV-positive blood \\
\hline & $10^{-0}$ & $10^{-1}$ \\
Real-time PCR $\left(\mathrm{C}_{\mathrm{T}}\right)$ & & \\
Automatically extracted DNAs & 30.37 & 34.96 \\
EZ-Fast-extracted DNAs & 24.59 & 26.18 \\
LAMP (Tp) & & \\
Automatically extracted DNAs & $13: 00$ & $17: 52$ \\
EZ-Fast-extracted DNAs & $14: 00$ & $15: 15$ \\
\hline
\end{tabular}

No. $\mathrm{C}_{\mathrm{T}}$, threshold cycle values undetectable using real-time PCR.

No. Tp, time-of-positivity values undetectable using LAMP.

+ , In duplicate analyses, one sample was positive, and one was negative using the LAMP reaction.

Fig. 1. Concept of the development of an on-site diagnostic test using a combination of simple DNA extraction with EZ-Fast and a portable battery-powered LAMP device, potentially applicable to a portable real-time PCR device.

\section{Hosted file}

20200408-TBED-Fig1-Yamazaki.pptx available at https : //authorea. com/users/310171/articles/440972development-of-an-on-site-diagnostic-system-for-infectious-diseases-evaluation-using-bloodsamples-containing-the-bovine-leukemia-dna 